\title{
Are the Predatory Publishers Collapsing or Re-Inventing Themselves?
}

\author{
Alexandru-Ionuţ Petrişor \\ “Ion Mincu” University of Architecture and Urban Planning, \\ Bucharest, Romania \\ alexandru.petrisor@uauim.ro
}

\begin{abstract}
Background. Despite their unceasing presence, predatory journals appear to no longer draw the attention of researchers. Their methods of luring authors have evolved, but they seem to lure fewer authors, with the vast majority of such authors coming from developing countries.

Objectives. This article uses the invasive species and adaptive cycle concepts from ecology to analyze the trends and possible evolution of predatory journals. Methods: Calls for papers received directly or present on the Web, dedicated scientific websites, and social media posts were the primary sources of data used in the analysis.

Results. Results of the trend analysis suggest that predatory journals have exhausted the potential of past methods to lure authors and are now at a stage of reinventing themselves; for example, transforming into proofreading services. Using the ecological metaphor, predatory journals are an invasive species in the research ecosystem, originating from the "dark" side of the economic ecosystem (Internet and e-mail-based scams). As a system, they are now approaching the creative destruction stage, and as a species they seem to have occupied their niche, relying on authors from the developing countries.

Contributions. The ecological analogy provides a theoretical base for understanding and predicting the behavior of predatory journals. From a practical perspective, the findings can be used to prevent authors from being lured by the "new generation" of predatory publishers.
\end{abstract}

\section{INTRODUCTION}

The ecological literature abounds with studies on the effects of introducing invasive species in an ecosystem (e.g., Rosenzweig, 2001; Allendorf \& Lundquist, 2003; Pimentel, Zuniga \& Morrison., 2005; Vilà et al., 2010). The new species colonizes a niche, eliminating other species using it, and then increases rapidly in number, causing damage to the system (Vilà et al., 2010) and economy (Pimentel et al., 2005); in the end, its population drops down and it becomes part of the system.

This behavior seems to be true with regard to predatory journals, defined as "those that exploit the gold open-access model to profit from scholarly publishing in a dishonest way" (Beall, 2016). After their emergence in the research ecosystem, numerous articles were devoted to them, some were even published in top rated journals (Beall, 2012; Bohannon, 2013; Kumar \& Saxena, 2016). Despite this attention, the number of predatory journals 


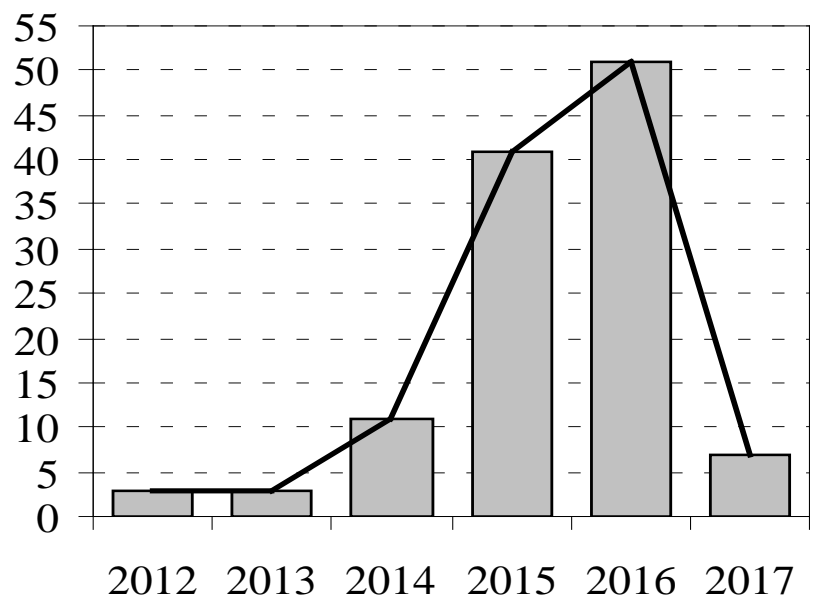

Figure. 1. Results of the Web of Science simultaneous search for "predatory publishing”, "predatory publishers" and "predatory journals". The graph shows the number of publications, indicating that the increasing trend is slowing down after 2015.

increased (Clark \& Smith, 2015) and their strategies evolved (Petrişor, 2016). Nowadays, less attention is paid to them: an analysis showing the interest paid to them in the literature using the approach developed by Lipitakis and Rivalle (2016) suggests that the increasing trend is slowing down (see Figure 1; the number for 2017 should be treated with caution as the data were incomplete). Even Beall's (2016) list and blog, updated periodically to expose the new predatory journals and publishers, disappeared without drawing too much attention (Teixeira da Silva, 2017).

The adaptive cycle was designed as part of the panarchy theory to explain the behavior of socio-ecological complexes, and its use extended from ecology to psychology, social and economic sciences (Chelleri, 2012), industry (Ashton, 2009), agriculture (Matthews \& Selman, 2006), management (Hahn \& Winn, 2010), rural development (Salvia \& Quaranta, 2015) and urban development (Ernstson et al., 2010), but was little explored in measuring science. The cycle consists of four phases: growth or exploitation (r), conservation (K), collapse or release $(\omega)$, and reorganization or creative destruction $(\alpha)$ (Holling et al., 2002). More important, the cycles of systems situated on different hierarchical levels influence each other; inferior systems tend to experience and "revolt", while superior systems tend to conserve and stabilize (Holling et al., 2002).

In order to explain what is happening and predict future trends, this paper aims to extend the work of Petrişor (2016) by using the invasive species and adaptive cycle concepts (Gunderson \& Holling, 2002) as a looking glass to analyze the dynamics of predatory journals in the ecological literature.

\section{METHODS}

E-mails received from predatory journals, and relevant content of the journal websites and social media sites were analyzed, similar to the method of Petrişor (2016). The analysis builds upon the stages identified in the aforementioned article, looking only at the new trends following its publication. 
The sources used in this study were:

1. Beall's blog post on the use of dumb names by predatory journals ${ }^{1}$. The actual site is no longer available, but an archived copy can be accessed through the Wayback Machine ${ }^{2}$.

2. Twitter posts by Stuart Palmer ${ }^{3}$ and Anthony Wilson ${ }^{4}$, and e-mail based call-for-papers from the Science Publishing Group.

3. Facebook post from the International Journal of Multidimensional Research ${ }^{5}$.

4. LinkedIn post from the Euro Asia Research and Development Association ${ }^{6}$.

5. Academia.edu post from the International Journals of Multi-Dimensional Research ${ }^{7}$.

6. Website of the International Journal of Advanced Research-Indexation ${ }^{8}$.

7. E-mail based offer of proofreading services from Savant Publishing House and the company website ${ }^{9}$, Savant Proofreading, Platinum Proofreading, Springredit Proofreading, Oxford Proofreading and Editing Services, and Donnish Services.

8. E-mail based call-for-papers from the International Journal of Modern Engineering Research, International Education and Research Journal, and Abhinav National, International Peer Reviewed Refereed Journal.

Text and image analysis were used to analyze the data from these sources and to identify similarities and repeating patterns, which suggest connections between the predatory publishers or evolutionary trends.

\section{RESULTS AND DISCUSSION}

An in-depth analysis performed previously identified numerous strategies used by the predatory publishers. In summary, they consist of:

- approaching strategies, including the choice of journal names, faked location in Western countries, fast publication, abstracting and indexing, personalization of the calls-for-papers, boasting invitations, generic editorship, and common design

- subjugation strategies, including hidden fees, a marketing centered on prices instead of quality, and use of business language, and

- general strategies, including the lack of or poor language editing, openness, high acceptance rates, promotion of published articles, author certificates, and other services (Petrişor, 2017).

\footnotetext{
${ }^{1}$ https://scholarlyoa.com/2016/09/20/oa-megajournals-running-out-of-unique-titles-nowusing-dumb-ones/

${ }^{2}$ http://web.archive.org/web/20161018025537/https://scholarlyoa.com/2016/09/20/oamegajournals-running-out-of-unique-titles-now-using-dumb-ones/

${ }^{3}$ https://twitter.com/s_palm/status/735761801086799873

${ }^{4}$ https://twitter.com/awilsonpoet/status/736140828654067712

${ }^{5}$ https://www.facebook.com/permalink.php?story_fbid=1769238116625213\& id $=1571018783200032$

${ }^{6}$ https://www.linkedin.com/pulse/thomson-reuters-researcherid-indexed-journal-monikachapagain

${ }^{7}$ https://www.academia.edu/18556327/Thomsonn_Reuters_ResearcherID_indexed_journal

${ }^{8} \mathrm{http}: / / \mathrm{www}$. journalijar.com/indexing/

${ }^{9} \mathrm{http} / / / \mathrm{www}$.savantproofreading.com/
} 

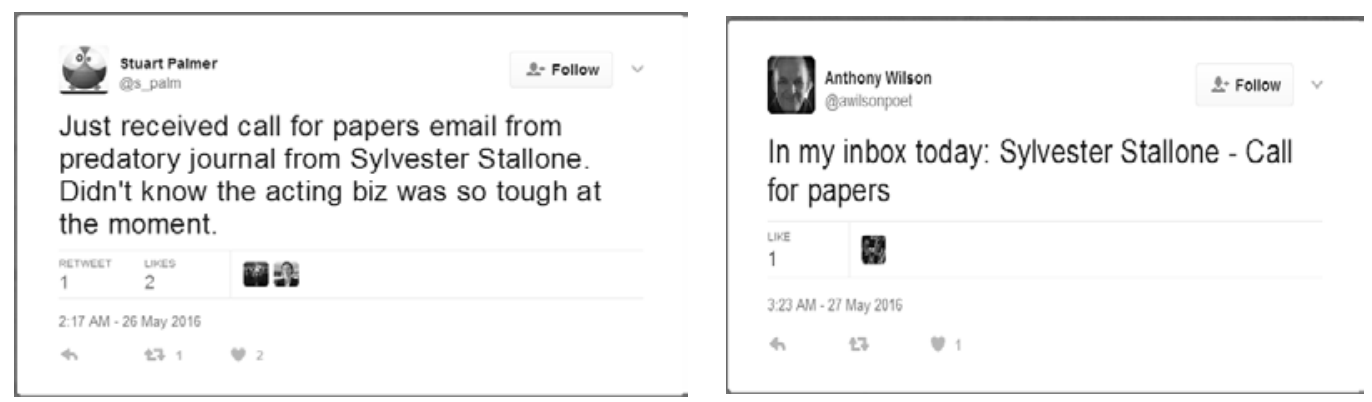

Figure. 2. Twitter posts by Stuart Palmer

(https://twitter.com/s_palm/status/735761801086799873) and Anthony Wilson (https://twitter.com/awilsonpoet/status/736140828654067712) reporting calls-forpapers signed by Sylvester Stallone

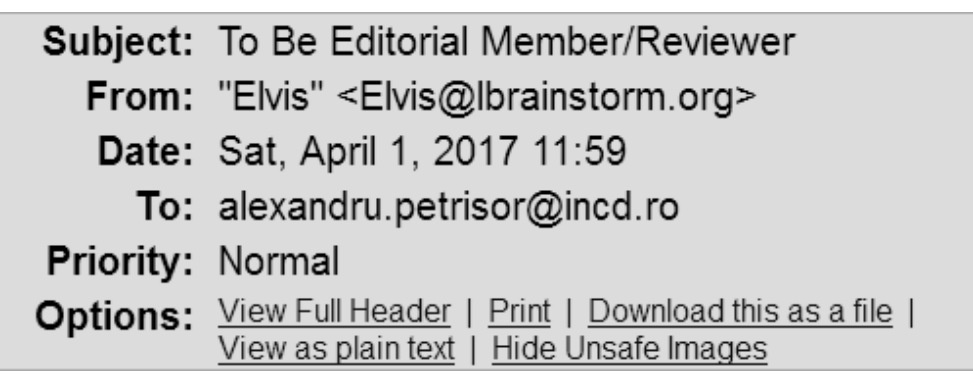

Figure 3. Science Publishing Group call-for-papers signed by “Elvis”

The new analysis based on calls-for-papers received during 2016-2017 revealed the evolving nature of predatory journals and publishers. Essentially, within the year, four new strategies became obvious in addition to the previous ones:

1. The predatory journals seem to have exhausted almost all possible combinations of words to form their titles, provided that the names indicate international and also multidisciplinary coverage (Schauss, 2014; Wehrmeijer, 2014; Crawford 2014). Take for example the name Abhinav National, International Peer reviewed Refereed Journal. The title contains a contradiction (i.e. national/international) and repeated terms (i.e. peer reviewed/refereed), indicating that the editors are unclear about their meaning. As a result, the "newer generation" predatory journals started to use "dumb" phrases such as "precious engineering" ${ }^{10}$, International Education and Research Journal and International Journal of Modern Engineering Research.

2. The authors of calls-for-papers started using spam-like names to sign their e-mails; a recent call was signed "Stallone Sylvester" (Figure 2), and another by "Elvis" (Figure 3 ). In terms of the names used to sign the call-for-papers and its e-mail address, these messages do not seem to differ substantially from the classical "Nigerian scam” (Smith, 2009), and use the same marketing strategies — very common or prominent names meant to draw attention.

${ }^{10}$ https://scholarlyoa.com/2016/09/20/oa-megajournals-running-out-of-unique-titles-nowusing-dumb-ones/ (the actual site doesn't work, but can be accessed through the Wayback Machine at: http://web.archive.org/web/20161018025537/https://scholarlyoa.com/2016/09/20/oamegajournals-running-out-of-unique-titles-now-using-dumb-ones/) 
3. Since the fake impact factors or impersonation of Clarivate Analytics indexed journals were already revealed, the predatory journals adopted a new strategy: they created a ResearcherID account and started to claim their indexation based on it (Figure 4).

4. The "publishing business" seems to be approaching the end for the predators, which are re-orienting their focus to "proofing and translation services". To illustrate, Savant Journals became Savant Publishing House and Donnish Journals became Donnish Services, both offering proofreading services and using a very similar graphic (Figure 5). Their number is increasing: calls were received during a single week from Platinum Proofreading, Springredit Proofreading, Oxford Proofreading and Editing Services, and Savant Proofreading (three in the same day). More recently, the sprawling proofing and translation services adopted the same tactics as the journals, including the use of common English names for advertisers (calls from Platinum Proofreading signed “Calvin Smith” or from Savant Proofreading signed “John Evans”).

The sub-par quality of these services is evident, since the offer of proofreading services from Savant Publishing House includes sentences like "The said manuscripts that are sent to us after been peer-reviewed by our team of renowned academics in the Editorial board, are then subsequently published in English Language”.

The four strategies presented above seem to suggest that predatory publishers are running out of their strategies, despite the increase in their number and the constant calls for papers. The analysis based on the adaptive cycle suggests possible reasons. In order to explain it, the facts presented so far are arranged in correspondence to the phases of the adaptive cycle:

1. Growth or exploitation (r): this stage corresponds to the growth of the predatory publishers, and diversification: journals, publishers, strategies, etc., as described in Petrişor (2017).

2. Conservation (K): at this stage, the "market" settled down. Several established authors were deceived after wasting their research in predatory journals; the reactions intensified and resulted in "earthquakes", such as the efforts of the Sweden-based Directory of Open Access Journals (DOAJ) which consequently revised its listing policy (Bohannon, 2013; Wehrmeijer, 2014) to avoid the association with the predatory open access journals. Many institutions reacted by advising authors to avoid publication in such journals and banning from academic promotion those who published in such journals despite previous warnings. At the same time, honest authors are unlikely to accept calls from such journals.

3. Collapse or release $(\omega)$ seems to be the end point, where predatory journals have exhausted the possibilities of their strategies (e.g., names, authors of the calls-forpapers), and, despite their unceasing presence, occupy a niche-authors from developing countries (Balehegn, 2017) who do not bring much profit as they usually pay lower fees.

4. Reorganization or creative destruction $(\alpha)$ is the stage where predatory publishers reorient their activity to other businesses, such as proofing and translation services. 


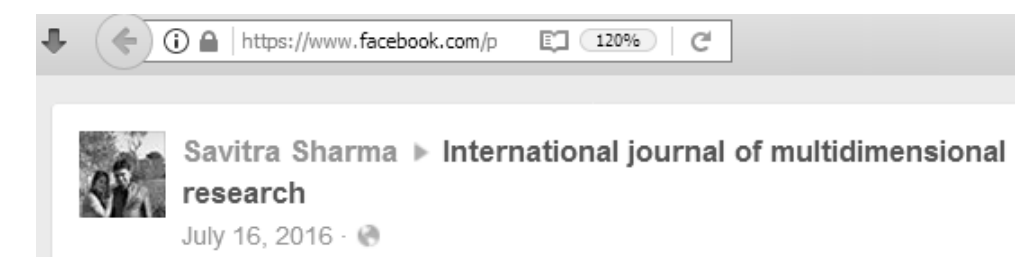

Thomson Reuters ResearcherID indexed journal,

ResearcherID: M-1436-2015
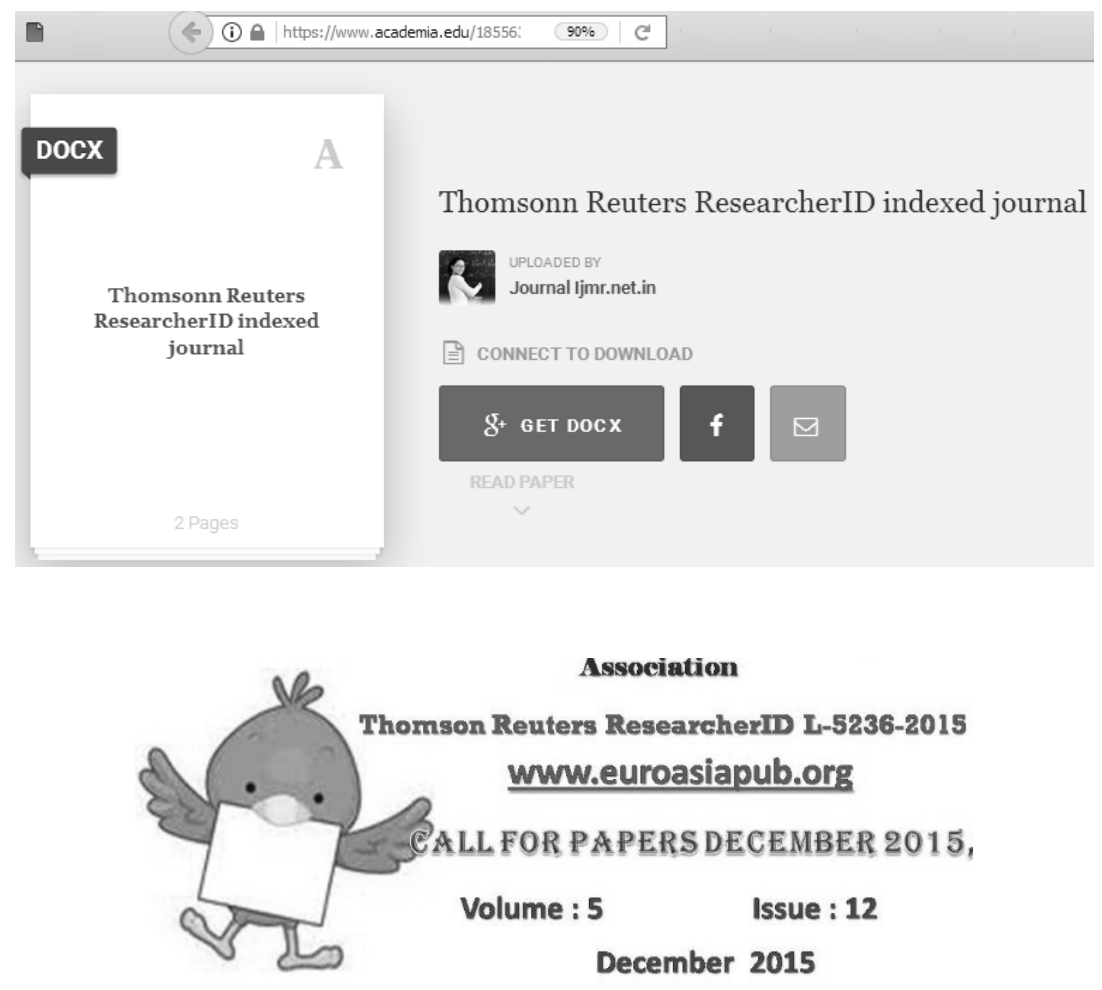

\section{Please Send Your Paper to EDITORIJRIM Q GMAIL.COM}

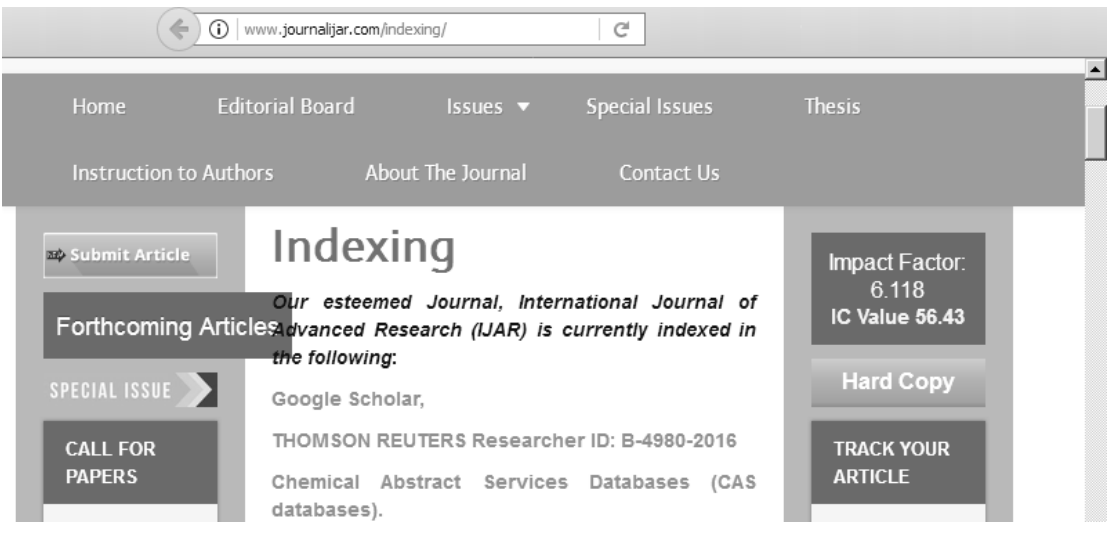

Figure. 4. Social media (top three) and website (bottom) advertisements from predatory journals claiming indexing by Clarivate Analytics (formerly Thomson Reuters) based on a ResearcherID account 


\section{SAVANT JOURNALS}

\author{
SAVANT PROOFREADING
}

SAVANT PROOFREADING

\title{
DONNISH JOURNALS
}

\section{DONNISH SERVICES}

\author{
DonnishJournals
}

Fig. 5. Savant Journals became Savant Publishing House and now offer proofreading services; Donnish Journals became Donnish Services and offer proofreading and editing services. The graphics from the e-mails offering their services do not differ too much (top and middle images), and the Savant website logo (http://www.savantproofreading.com/) resembles the one of Donnish Journals (bottom).

Predatory publishers have been criticized severely for their lack of ethics and quality control (peer review). However, their emergence can be viewed as a reaction to the increasing demand for publication outlets, supported by the current research funding schemes where the funding agencies finance the dissemination of research. In initial e-mails, predatory publishers did not charge the researcher, but asked for their "share" of the dissemination funds. In support of this statement, predatory publishers are now covering niches not supported by the already established journals: fast-track publication and promotion, a way of achieving some recognition in developing countries, but charge a fee in return for these "services". Since their citation rates are lower than those of the established journals (Gasparyan et al., 2016) but increased artificially by self-citation (Djuric, 2015), authors seeking to make their research known are avoiding them.

Speculating further, Petrişor (2017) suggested that "there is a possibility that some of these businesses (i.e. predatory publishers) are coordinated together"; nowadays, apart from the "Nigerian scam", spammers cannot find a universal lure that transcends cultural and national barriers. Science has this advantage, and the similarities strengthen the legitimacy of asking whether predatory journals, which also have an obscure financing, are not part of a "worldwide scam".

Combining the two conclusions based on the ecological analogy, predatory journals seem to be an "alien species" colonizing a niche in the research ecosystem-the "dark side of publishing". Unlike an "invasive species", it did not cause damage to the existing species (already established journals) despite predating its authors. To continue to be successful, they need to re-invent themselves.

A practical question remains; what actions can be taken against the predatory journals and publishers? So far, only isolated actions have been taken. Based on the recommendations of the Algerian Ministry of Higher Education and Research (2016), Algerian universities simply do not count publications in journals where authors have to pay for publications, for academic promotion or doctoral degrees. Western universities advised their students and faculty members against predatory publishers and journals (Australian Universities Centre, 2017; Iowa State University of Science and Technology, 2017; The University of Manchester Library, 2017; University of Saskatchewan, 2017). However, it is very difficult to distinguish them, because even the definition is weak. Beall's (2016) list included all journals and publishers who charged a fee, including some with recognized quality. A universal solution may not be available. 


\section{ACKNOWLEDGEMENTS}

Despite the publication of the previous article (Petrişor, 2016), reflecting an attitude against them, predatory journals and publishers have not ceased assaulting me with calls-for-papers. I am thankful to them, as they serve as a cost-free database for researching their behavior. Moreover, thanks are due to the anonymous reviewers who contributed substantially to improving the quality of the manuscript through valuable comments and suggestions.

\section{REFERENCES}

Algerian Ministry of Higher Education and Research (2016). Classification of journals (in French). Retrieved from https://www.crbt.dz/images/valorisation/Catégorisation\%20des\%20revuesDGRSDT.pdf

Allendorf, F.W., \& Lundquist, L.L. (2003). Introduction: Population biology, evolution, and control of invasive species. Conservation Biology, 17(1), 24-30.

Ashton, W.S. (2009). The structure, function and evolution of a regional industrial ecosystem. Journal of Industrial Ecology, 13(2), 228-246.

Australian Universities Centre (2017). Frequently asked questions: Predatory journals. Retrieved from http://www.abdc.edu.au/pages/faqs.html\#predatory

Balehegn, M. (2017). Increased publication in predatory journals by developing countries' institutions: What it entails? And what can be done? International Information \& Library Review, 49(2), 97-100. doi:10.1080/10572317.2016.1278188

Beall, J. (2012). Predatory publishers are corrupting open access. Nature, 489(7415), 179.

Beall, J. (2016). Essential information about predatory publishers and journals. International Higher Education, 86, 2-3.

Bohannon, J. (2013). Who's afraid of peer review? Science, 342(6154), 60-65.

Chelleri, L. (2012). From the "resilient city” to urban resilience: A review essay on understanding and integrating the resilience perspective for urban systems. Documenti d'Anàlisi Geogràfica, 58(2), 287-306.

Clark, J., \& Smith, R. (2015). Firm action needed on predatory journals. British Medical Journal, 350, h210.

Crawford, W. (2014). Journals, “journals” and wannabes: Investigating the list. Cites \& Insights, 14(7), 1-45.

Djuric, D. (2015), Penetrating the omerta of predatory publishing: The Romanian connection. Science \& Engineering Ethics, 21(1), 183-202.

Ernstson, H., Van der Leeuw, S. E., Redman, C. L., Meffert, D. J., Davis, G., Alfsen, C., \& Elmqvist, T. (2010). Urban transitions: On urban resilience and human-dominated ecosystems. Ambio, 39(8), 531-545.

Gasparyan, A.Y., Nurmashev, B., Voronov, A.A., Gerasimov, A.N., Koroleva, A.M., \& Kitas G.D. (2016). The pressure to publish more and the scope of predatory publishing activities. Journal of Korean Medical Science, 31(12), 1874-1878.

Gunderson, L.H., \& Holling, C.S. (Eds.). (2002). Panarchy: Understanding transformations in human and natural systems. Washington, D.C.: Island Press.

Hahn, T., Kolk, A., \& Winn, M. (2010). A new future for business? Rethinking Management theory and business strategy. Business \& Society, 49(3), 385-401.

Iowa State University of Science and Technology (2017). Understanding predatory publishers. Retrieved from http://instr.iastate.libguides.com/predatory 
Kumar, P., \& Saxena, D. (2016). Pandemic of publications and predatory journals: Another nail in the coffin of academics. Indian Journal of Community Medicine, 41(3), 169171.

Lipitakis, E., \& Rivalle, G. (2016). The importance of earlier literature: A case study on scientific research output in Web of Science for Romania. Retrieved from http://www.e-nformation.ro/wp-content/uploads/2016/09/Report-The-Importance-ofEarlier-Literature.pdf

Matthews, R., \& Selman, P. (2006). Landscape as a focus for integrating human and environmental processes. Journal of Agricultural Economics, 57(2), 199-212.

Petrişor, A.-I. (2016). Evolving strategies of the predatory journals. Malaysian Journal of Library and Information Science, 21(1), 1-17.

Pimentel, D., Zuniga, R., Morrison, D. (2005). Update on the environmental and economic costs associated with alien-invasive species in the United States. Ecological Economics, 52(3), 273-288.

Rosenzweig, M.L. (2001). The four questions: What does the introduction of exotic species do to diversity? Ecology and Evolutionary Biology, 3(3), 361-367.

Salvia, R., \& Quaranta, G. (2015). Adaptive cycle as a tool to select resilient patterns of rural development. Sustainability, 7, 11114-11138.

Schauss, G. A. (2014). Beware of predators. Nutritional Outlook, 17(7), 22-27.

Smith, A. (2009). Nigerian scam e-mails and the charms of capital. Cultural Studies, 23(1), 27-47.

Teixeira da Silva, J.A. (2017). The ethical and academic implications of the Jeffrey Beall (www.scholarlyoa.com) blog shutdown. Science and Engineering Ethics. Advance online publication. doi:10.1007/s11948-017-9905-3 (in press)

The University of Manchester Library (2017). Advice on predatory journals and publishers. Retrieved from http://www.library.manchester.ac.uk/using-thelibrary/staff/research/services/open-access-at-manchester/check-your-journal/adviceon-predatory-journals/

Vilà, M., Basnou, C., Pyšek, P., Josefsson, M., Genovesi, P., Gollasch, S., ... DAISIE partners. (2010). How well do we understand the impacts of alien species on ecosystem services? A pan-European, cross-taxa assessment. Frontiers in Ecology and the Environment, 8(3), 135-144.

University of Saskatchewan (2017). Predatory publishers: Home. Retrieved from https://libguides.usask.ca/predatorypublishers

Wehrmeijer, M. (2014). Exposing the predators: Methods to stop predatory journals. Unpublished Master's thesis, Leiden University, Leiden, The Netherlands. Retrieved from https://openaccess.leidenuniv.nl/handle/1887/28943 